\title{
Electroconvulsive Therapy
}

National Cancer Institute

\section{Source}

National Cancer Institute. Electroconvulsive Therapy. NCI Thesaurus. Code C93303.

A procedure in which a series of short duration electric currents are passed via electrodes

through the brain to cause a controlled seizure for the purpose of treating severe,

intractable forms of mental illness, including depression, mania, and catatonia. 